\title{
Status epilepticus in scleromyxedema
}

\author{
Sofia Markoula ${ }^{1}$, Sofia Zouroudi ${ }^{1}$, Sotirios Giannopoulos ${ }^{1}$, Kimon Tsoukanelis ${ }^{1}$, Ananstasia Zikou², \\ Athanassios P. Kyritsis ${ }^{1}$
}

${ }^{1}$ Department of Neurology, University Hospital of Ioannina, 45110 Ioannina, Greece.

${ }^{2}$ Department of Radiology, University Hospital of Ioannina, 45110 Ioannina, Greece.

\section{A B S T R A C T}

Scleromyxedema is a rare dermatologic disorder, characterized by erythematous or yellowish lichenoid waxy papules. Neurological manifestations are rare but well-recognized. A 51-year-old woman, diagnosed with scleromyxedema, was admitted to the hospital with status epilepticus, caused by brain lesions, as disclosed in a brain magnetic resonance imaging (MRI). The patient was treated with anticonvulsants and corticosteroids and gradually recovered fully. A complete remission of the lesions was shown in a follow-up brain MRI. In cases with scleromyxedema and the presence of neurological manifestations, we need to pay attention to central nervous system involvement, especially when combined with brain MRI lesions, and treat the patient appropriately.

Key words: Scleromyxedema; epilepsy; status epilepsticus; dermatologic disorder

\section{INTRODUCTION}

Scleromyxedema is a rare dermatologic disorder, characterized by erythematous or yellowish lichenoid waxy papules. Neurological manifestations are rare but well-recognized in patients with scleromyxedema, among other extracutaneous complications. ${ }^{[1-4]}$

We report a patient with scleromyxedema presenting with refractory status epilepticus, caused by brain lesions, probably related to the disease.

\section{CASE REPORT}

A 51-year-old right handed Caucasian woman was admitted to the hospital with subacute onset of confusion, slurred speech and expressive aphasia that had developed in a period of 3 days. The patient had been diagnosed with scleromyxedema for 15 years and had been under regular follow up and monthly administration of immunoglobulin. Her general physical examination at admission showed changes in the cutaneous presentation of her scleromyxedema. This patient presented with diffuse confluent papulosquamous eruption and thickening of the skin on the face, body, arms and the

Corresponding Author: Dr. Sofia Markoula, Department of Neurology, University Hospital of loannina, 45110 loannina, Greece. E-mail: smarkoula@grads.voi.gr

\begin{tabular}{|l|l|}
\hline \multicolumn{2}{|c|}{ Access this article online } \\
\hline Quick Response Code: & Website: \\
\hline & www.nnjournal.net \\
\hline
\end{tabular}

legs with impaired joint mobility of her fingers, perhaps as a consequence of the skin thickening associated with her scleromyxedema. With regard to the neurological manifestations, aphasia and bilateral pyramidal weakness were found.

The patient became rapidly disorientated and developed generalized tonic-clonic seizures leading to convulsive status epilepticus. Intravenous diazepam and phenytoin (according to status epilepticus treatment protocol) was administered and status epilepticus was not resolved and general anesthesia and intubation in the intensive care unit was required to achieve seizures control.

Using magnetic resonance imaging (MRI), low signal intensity on T1-weighted images and high signal intensity on T2-weighted and fluid-attenuated inversion recovery images of the brain revealed bilateral fronto-parietal and left fronto-occipital cortical lesions [Figures 1 and 2]. Furthermore, "hyperintense vein sign" was observed in right frontal area, compatible with slow flow in isolated cortical veins [Figure 1]. After intravenous gadolinium administration, no abnormal enhancement was revealed [Figure 2].

Following a lumbar puncture, mildly elevated protein

This is an open access article distributed under the terms of the Creative Commons Attribution-NonCommercial-ShareAlike 3.0 License, which allows others to remix, tweak, and build upon the work non-commercially, as long as the author is credited and the new creations are licensed under the identical terms.

For reprints contact: service@oaepublish.com

Cite this article as: Markoula S, Zouroudi S, Giannopoulos S, Tsoukanelis K, Zikou A, Kytritsis AP. Status epilepticus in scleromyxedema. Neuroimmunol Neuroinflammation 2016;3:124-6.

Received: 29-09-2015; Accepted: 04-03-2016 


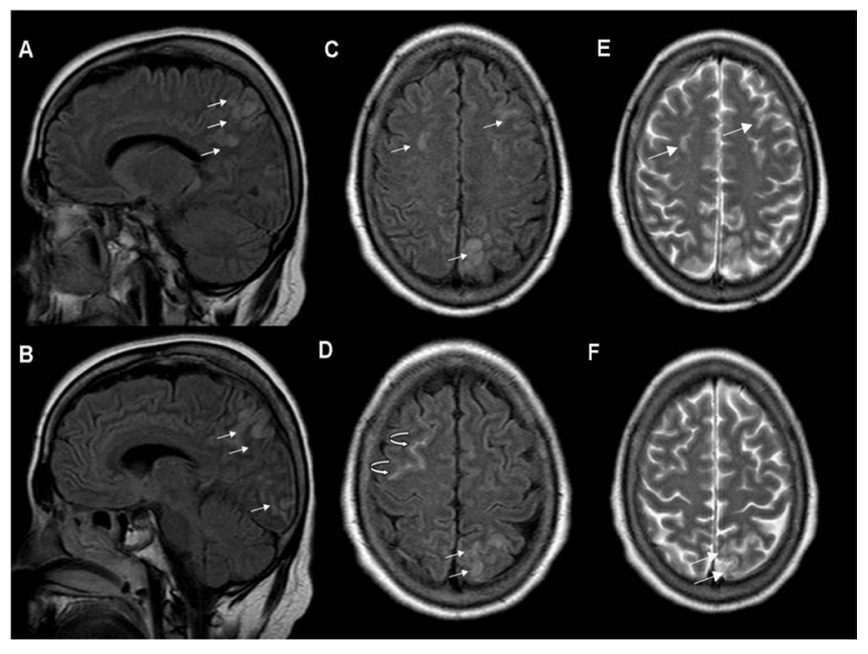

Figure 1: Sagittal fluid-attenuated inversion recovery (FLAIR) (A, B), axial FLAIR $(C, D)$ and T2-weighted images $(E, F)$ revealed multiple focal cortical areas of high signal intensity fronto-parietal and occipital (arrows) and "hyper-intense vein" compatible with slow flow in isolated cortical vein (curved arrow).

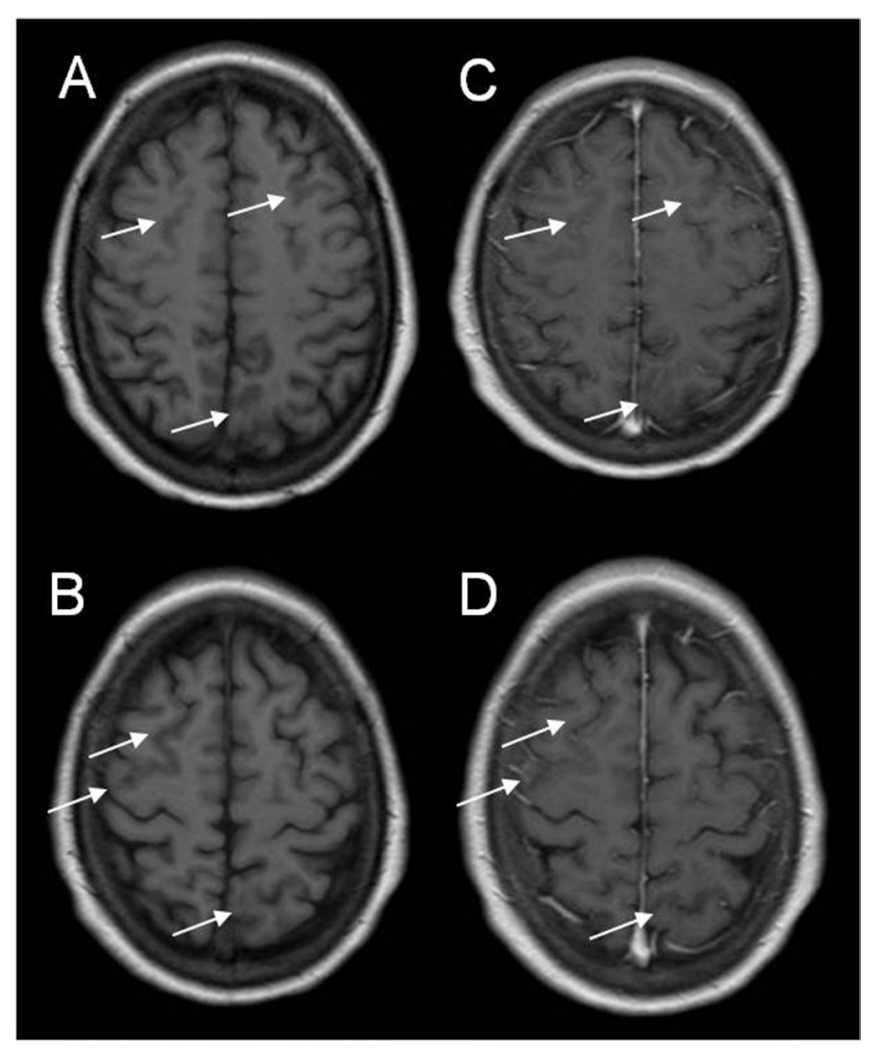

Figure 2: Axial T1-weighted images before (A, B) and after intravenous gadolinium administration (C, D) showed cortical areas with low signal intensity (arrows) without abnormal enhancement

(TPR $77 \mathrm{mg} / \mathrm{dL}$ ) was recorded and all other constituents of cerebrospinal fluid (CSF) were found within normal ranges. All CSF stains for microorganisms and polymerase chain reaction assays for herpes simplex virus type 1 (HSV-1), HSV-2, varicella-zoster virus, human cytomegalovirus and Epstein-Barr virus were also negative. Additional laboratory tests disclosed no other significant findings apart from monoclonal immunoglobulin G (IgG) gammapathy with lambda light chains and excessive proteinuria.

The patient remained under general anesthesia for $48 \mathrm{~h}$.

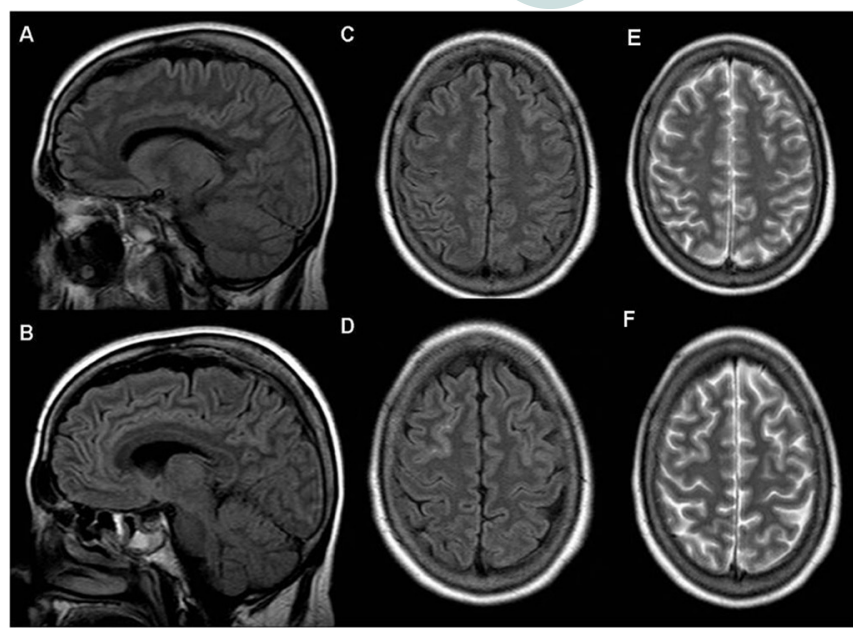

Figure 3: Sagittal fluid-attenuated inversion recovery (FLAIR) (A, B), axia FLAIR (C, D) and T2-weighted images (E, F) one month later, showed near total remission of the lesions.

Electroencephalogram after this 48 h-period showed that status epilepticus was resolved and demonstrated spikes followed by slow waves, over the left fronto-parietal region. The patient was transferred to the department of neurology under treatment with levetiracetam and corticosteroids (40 mg of dexamethasone). She demonstrated a gradual recovery and over the following week her language and motor function improved dramatically and the dosing of corticosteroids were reduced with decrements of $10 \mathrm{mg}$ every 3 days.

The patient was discharged, after 25 days of hospitalization, without any neurological semiology. The follow up brain MRI one month later demonstrated almost complete remission of signal abnormalities [Figure 3]. The anticonvulsant treatment was tapered of (redcued) over a three month period without any further seizure occurrence.

\section{DISCUSSION}

Scleromyxedema also known as lichen myxedematosus or papular mucinosis is a rare skin disorder involving the face and the extremities that is characterized by erythematous or yellowish lichenoid waxy papules. ${ }^{[1,2]}$ The pathogenesis of scleromyxedema remains unclear. ${ }^{[5]}$ A proliferation of fibroblasts, deposition of acid mucopolysaccharides in the upper dermis and a monoclonal paraproteinemia-most often IgG monoclonal gammopathy are the predominant findings..$^{[2,5]}$ Extracutaneous manifestations are due to cardiovascular, rheumatologic, renal, hematologic and neurologic involvement. ${ }^{[1-4]}$ Encephalopathy, transient focal neurological disturbances, progressive cognitive decline, seizures, peripheral neuropathy, carpal tunnel syndrome and myopathy are included in the neurological manifestations. ${ }^{[2,4]}$ They could be partially explained by the paraproteinemia and the disruption of the blood-brain barrier with elevated CSF protein concentration in the central nervous 
system (CNS) disorders or by the deposition of mucopolysaccharides within the nerve and muscle fibers in peripheral nervous system conditions. ${ }^{[2,3]}$ The treatment of CNS involvement in scleromyxedema patients includes steroids, plasmapheresis, intravenous immunogloblin and chemotherapeutic drugs in various combinations. ${ }^{[4]}$

Brain imaging in patients with CNS involvement rarely shows lesions responsible for this condition and in the rare cases with lesions demonstrated, spontaneous remission remains unlikely. ${ }^{[2,4]}$ In conclusion, in cases with scleromyxedema that present with neurological manifestations, we should consider central nervous system pathophysiology and evaluate possible bsrain abnormalities with detailed magnetic resonance images and treat the patient appropriately.
Financial support and sponsorship

Nil.

Conflicts of interest

There are no conflicts of interest.

\section{REFERENCES}

1. Cokonis G, Falaska G, Georgakis A, Heymann WR. Scleromyxedema. Clin Dermatol 2006;24:493-7.

2. Berger JR, Dobbs MR, Terhune MH, Maragos WF. The neurologic complications of scleromyxedema. Medicine 2001;80:313-9.

3. Johkura K, Susuki K, Hasegawa O, Kuroiwa Y, Komatsumoto S. Encephalopathy in scleromyxedema. Neurology 1999;53:1138-40.

4. Fleming KE, Virmani D, Sutton E, Langley R, Corbin J, Pasternak S, Walsh NM. Scleromyxedema and the dermato-neuro syndrome: case report and review of the literature. J Cutan Pathol 2012;39:508-11.

5. Hummers LK. Scleromyxedema. Curr Opin Rheumatol 2014;26:658-62. 